\title{
Constraining regional greenhouse gas emissions using geostationary concentration measurements: a theoretical study
}

\author{
P. J. Rayner ${ }^{1}$, S. R. Utembe ${ }^{1}$, and S. Crowell ${ }^{2}$ \\ ${ }^{1}$ School of Earth Sciences, University of Melbourne, Melbourne, Australia \\ ${ }^{2}$ College of Atmospheric and Geographic Sciences, University of Oklahoma, Norman, USA \\ Correspondence to: P. J. Rayner (prayner@unimelb.edu.au)
}

Received: 24 December 2013 - Published in Atmos. Meas. Tech. Discuss.: 12 February 2014

Revised: 4 July 2014 - Accepted: 9 July 2014 - Published: 2 October 2014

\begin{abstract}
We investigate the ability of column-integrated trace gas measurements from a geostationary satellite to constrain surface fluxes at regional scale. The proposed GEO$\mathrm{CARB}$ instrument measures $\mathrm{CO}_{2}, \mathrm{CO}$ and $\mathrm{CH}_{4}$ at a maximum resolution of $3 \mathrm{~km}$ east-west $\times 2.7 \mathrm{~km}$ north-south. Precisions are $3 \mathrm{ppm}$ for $\mathrm{CO}_{2}, 10 \mathrm{ppb}$ for $\mathrm{CO}$ and $18 \mathrm{ppb}$ for $\mathrm{CH}_{4}$. Sampling frequency is flexible. Here we sample a region at the location of Shanghai every 2 daylight hours for 6 days in June. We test the observing system by calculating the posterior uncertainty covariance of fluxes. We are able to constrain urban emissions at $3 \mathrm{~km}$ resolution including an isolated power plant. The $\mathrm{CO}$ measurement plays the strongest role; without it our effective resolution falls to $5 \mathrm{~km}$. Methane fluxes are similarly well estimated at $5 \mathrm{~km}$ resolution. Estimating the errors for a full year suggests such an instrument would be a useful tool for both science and policy applications.
\end{abstract}

\section{Introduction}

It is now widely agreed that satellite measurements of greenhouse gas concentrations in the atmosphere can help answer important biogeochemical questions (Rayner and O'Brien, 2001; Houweling et al., 2004; Miller et al., 2007; Kuze et al., 2009). Measurements from the Greenhouse Gas Observing Satellite (the first purpose-built instrument to do this) have required careful attention but are now beginning to yield important science (e.g., Parazoo et al., 2013). This science has important policy implications since it can provide the missing baseline for the natural $\mathrm{CO}_{2}$ removal, a baseline against which any climate mitigation policy must be assessed.
The direct role of these measurements in greenhouse gas mitigation is less clear. For this any measurement needs to allow attribution of a change in a flux at a scale and precision compatible with carbon policy. Hungershoefer et al. (2010) showed how difficult this could be at the national scale using the current generation of low-earth orbit satellites such as GOSAT. They showed that the precision of national estimates required relatively long missions to observe the magnitudes of flux changes agreed, for example, under the Kyoto Protocol. The relatively sparse coverage of the low-earth orbit missions such as the 16-day revisit time for the Orbiting Carbon Observatory (OCO) (Miller et al., 2007) presumably made the problem even more severe at smaller scales if governments wished to regionally attribute emission changes.

One proposal to improve this was not to change the revisit time but to introduce a limited imaging capability. The first generation of $\mathrm{CO}_{2}$ satellites used their detector area to spatially oversample a small swath, improving their signal-tonoise ratio. Bovensmann et al. (2010) proposed CarbonSat as a second-generation instrument where the swath is broadened. It produces a so-called push-broom sample with a $2 \mathrm{~km}$ resolution over a $500 \mathrm{~km}$ swath width. This capability has since been tested by airborne measurements (Krings et al., 2011).

CarbonSat's imaging capability gives it the capacity to localize sources. This capacity can be strengthened by capturing high-frequency variations of the concentration field. This idea was introduced to carbon-cycle estimation in the theoretical study of Law et al. (2003). They showed that an in situ measurement at a point could constrain the structure of surrounding sources simply because changing flow sampled different parts of the source field at different times. This idea 
has been demonstrated in studies like Lauvaux et al. (2009b) and Schuh et al. (2013), who showed that not only regional totals but the regional structure of emissions could be determined from limited numbers of in situ instruments coupled with regional transport models.

The foregoing discussion suggests that an instrument that can map aspects of a tracer field at high temporal resolution might provide strong constraints on regional fluxes. The arrival of geostationary measurements in the thermal infrared seems promising at first glance since these often contain channels sensitive to greenhouse gases such as $\mathrm{CO}_{2}$ and $\mathrm{CH}_{4}$. Unfortunately previous work with their low-earth orbit counterparts shows that such measurements do not constrain tracer distributions in the lower atmosphere (Engelen et al., 2009) or surface fluxes (Chevallier et al., 2009). Any proposed approach must couple the imaging capability of these geostationary instruments with the sensitivity to $\mathrm{CO}_{2}$ near the surface of the near-infrared instruments such as OCO and GOSAT.

This instrumental challenge is addressed by an instrument concept described in Kumer et al. (2013) and analyzed in Polonsky et al. (2013). The instrument compensates the greater distance from the observation enforced by its geostationary position by a longer time spent accumulating photons from each scene. The greater altitude of the geostationary orbit also limits the horizontal resolution of the instrument and increases the field of view compared to OCO-2 (although it is still substantially smaller than GOSAT). Kumer et al. (2013) describe an instrument which measures $\mathrm{CO}_{2}, \mathrm{CH}_{4}$ and $\mathrm{CO}$ simultaneously. Given these characteristics, what kind of resolution and precision can we obtain on regional fluxes? What is the complementary role of simultaneous measurement in attributing sources, especially for complete and incomplete combustion? This paper attempts to answer these two questions.

The outline of the paper is as follows: Sects. 2 and 3 describe the various tools we use, a recap of the instrument characteristics relevant to the study, a description of the simplified and efficient regional transport model we have developed for the study and the methods we use to estimate the density of observations such an instrument is likely to obtain. Section 4 describes a case study of an urban region with a power plant to assess both the resolution and attribution. Section 5 describes a case study for methane emissions. Section 6 considers the generality and limitations of the case studies.

\section{Methods and tools}

Our task here is to calculate the posterior uncertainty for the multivariate distribution of fluxes. For example, we follow Enting et al. (1995), Rayner et al. (1996), and Rayner and O'Brien (2001). Assuming a linear mapping between sources and concentrations (correct for inert tracers under atmospheric transport) and Gaussian probability distributions for all statistical quantities, we can use the analytic expression

$\mathbf{C}^{-1}(\boldsymbol{S})=\mathbf{C}_{0}^{-1}(\boldsymbol{S})+\mathbf{J}^{T} \mathbf{C}^{-1}(\boldsymbol{D}) \mathbf{J}$,

where $\mathbf{C}$ represents an uncertainty covariance matrix, $\boldsymbol{S}$ sources, $\boldsymbol{D}$ data (here column-integrated concentration), $\mathbf{J}$ the Jacobian or sensitivity of $\boldsymbol{D}$ to $\boldsymbol{S}$ and the subscript 0 represents a prior estimate. Equation (1) states that the information available on a quantity (the inverse of the uncertainty covariance) is given by that available a priori plus that obtained from the data. We make use of the fact that Eq. (1) does not depend on prior estimates or data so that we can carry out the calculations before any measurements are made provided we can define the error statistics and the sensitivity or Jacobian. The rest of this section describes these components.

For CO the above development is an approximation. This is because we solve for the $\mathrm{CO}$ emission factor as well as the $\mathrm{CO}_{2}$ flux. Thus the $\mathrm{CO}$ concentration is given by

$\boldsymbol{D}_{\mathrm{CO}}=\mathbf{J} \boldsymbol{S E}$,

where $\boldsymbol{E}$ is a $\mathrm{CO}$ emission factor which may vary at the same scale as $\boldsymbol{S}$; that is we solve for a separate emission factor for every grid cell. Linearizing this expression around the prior value, we obtain

$$
\begin{aligned}
& \frac{\partial \boldsymbol{D}_{\mathrm{CO}}}{\partial \boldsymbol{S}}=\mathbf{J} \boldsymbol{E}_{0} \\
& \frac{\partial \boldsymbol{D}_{\mathrm{CO}}}{\partial \boldsymbol{E}}=\mathbf{J} \boldsymbol{S}_{0} .
\end{aligned}
$$

Note that we use the same $\mathbf{J}$ for $\mathrm{CO}$ and $\mathrm{CO}_{2}$. This implicitly assumes CO is chemically inert on the timescale of our observations, which is only a few hours.

\subsection{Instrument}

The uncertainty covariance for data $\mathbf{C}(\boldsymbol{D})$ has contributions both from the measurement uncertainty and that of the transport model (Tarantola, 2004, Eq. 1.104). The measurement uncertainty is in turn determined by the properties of the instrument and the capability of the retrieval to estimate greenhouse gas concentration. Instrumental characteristics also determine the sampling density and frequency.

Kumer et al. (2013) describe the general characteristics of the instrument. For our purposes there are three key characteristics.

\subsubsection{Sampling density}

This refers to the distance between the centers of adjacent measurements on the ground. For GEOCARB it is $3 \mathrm{~km}$ in the east-west and $2.7 \mathrm{~km}$ in the north-south directions at the subsatellite point. 


\subsubsection{Resolution}

This refers to the size of a viewing pixel on the ground. For GEOCARB it is $5 \mathrm{~km}$ in the east-west and $4 \mathrm{~km}$ in the northsouth directions at the subsatellite point. These distances represent the full width at half maximum. The relationship between the resolution and sampling density means that adjacent pixels will overlap. Both the pixel size and spacing increase as we move away from the subsatellite point according to the projection of a fixed viewing angle onto the surface of the Earth, i.e., as $1 / \cos (\zeta)$, where $\zeta$ is the satellite zenith angle.

\subsubsection{Precision}

This refers to the expected error of a single sounding. Analysis in Kumer et al. (2013) and Polonsky et al. (2013) suggests precisions better than $3 \mathrm{ppm}$ for $\mathrm{CO}_{2}, 10 \mathrm{ppb}$ for $\mathrm{CO}$ and $18 \mathrm{ppb}$ for $\mathrm{CH}_{4}$. We use these precisions in subsequent analyses to allow some role for errors in the transport model.

\subsection{The SatPlume model}

For the theoretical studies of this paper, we need an efficient model to calculate $\mathbf{J}$ at high resolution. It is not necessary that the model captures the details of the relationship between a particular source and observation for given atmospheric conditions, but it should capture the statistics of this relationship - questions like the rate of diffusion of a plume of tracer as it is advected, the variability of the direction of advection etc. We will use the shorthand SatPlume to denote the model. While there is a great deal of collective experience in modeling tracer plumes, the target is almost always a concentration at a point. Our task of modeling column-integrated concentration has received much less attention and has almost no observational constraint. The high resolution of the satellite sampling means we cannot ignore the three-dimensional nature of the plume since the slant path of the sun-earthsatellite ray will traverse plumes from many sources at the resolution we use.

We seek the tracer distribution from a single source which is emitted continuously over some time interval. Note that the source could be smaller than a single grid cell in the model. We represent the tracer distribution by a Gaussian plume. The plume is represented by a curve in three dimensions describing the trajectory of its centroid and a transverse spread. The concentration is described by a series of piecewise, twodimensional Gaussian functions defined between successive positions of the centroids. Thus if the centroid is located at the point $\boldsymbol{X}_{1}$ at time $t_{1}$ and $\boldsymbol{X}_{2}$ at time $t_{2}$, we define the concentration as

$c(x, y, z)=\frac{Q}{L \sigma_{\xi} \sigma_{\zeta}} \exp \left[-\frac{\xi^{2}}{\sigma_{\xi}^{2}}-\frac{\zeta^{2}}{\sigma_{\zeta}^{2}}\right]$, where $Q$ is a normalization constant which guarantees that the integrated mass equals the integrated emission, $L$ is the Euclidean distance between $\boldsymbol{X}_{1}$ and $\boldsymbol{X}_{2}, \xi$ and $\zeta$ are the transverse and vertical distances, respectively, from the line connecting $\boldsymbol{X}_{1}$ and $\boldsymbol{X}_{2}$.

The spread has two dimensions $\sigma_{\xi}$ and $\sigma_{\zeta}$ since we need the vertical extent of the plume as well as its horizontal extent. The centroid is advected by the wind as

$\boldsymbol{x}(t+\delta t)=\boldsymbol{x}(t)+\delta t \boldsymbol{u}$,

where $\boldsymbol{x}(t)$ is the position at time $t, \boldsymbol{u}$ is the three-dimensional wind and $\delta t$ is the model time step.

There are three processes responsible for the spread of the plume: turbulence, divergence and shear. For divergence and shear we use a linear growth model

$\boldsymbol{\Sigma}(t+\delta t)=\boldsymbol{\Sigma}(t)+\delta t\left[\phi_{\mathrm{S}}(t)+\phi_{\mathrm{D}}(t)\right]$,

where $\boldsymbol{\Sigma}$ is the two-dimensional vector representing the Gaussian plume spread and $\phi_{\mathrm{D}}$ and $\boldsymbol{\phi}_{\mathrm{S}}$ are the rates of dispersion due to divergence and shear, respectively.

The divergence of the local wind will serve to dilute the plume. The two components we care about here are the vertical and the transverse. It is important to note that mass continuity for total air mass means the local concentration may not change but the plume structure may well. This is most clearly seen for subsidence near the ground where the vertical plume extent may be suppressed while the required horizontal divergence means the plume may spread horizontally. The divergence of the plume in the direction of advection is automatically treated by the advection equation since, if the centroids become further apart, the linear density of the plume will reduce (this is the role of $L$ in Eq. 4).

The vertical shear of the horizontal wind will act to spread the plume as different levels are effectively advected in different directions. We only consider velocities normal to the local direction of advection. Thus

$\phi_{\mathrm{S}}=\sqrt{\int_{0}^{\infty} \mu(z) \frac{\partial u^{\prime 2}}{\partial z} \mathrm{~d} z}$,

where $\mu(z)$ is the fraction of the plume mass at altitude $z$, and $u^{\prime}$ is the component of the horizontal velocity normal to the current direction of advection of the centroid.

For the spreading due to turbulence, we use a simple random walk model. This means that the square of the spread (the plume variance) grows linearly with time as

$\Sigma^{2}(t+\delta t)=\Sigma^{2}(t)+\delta t \Phi_{\mathrm{T}}(t)$,

where $\Phi_{\mathrm{T}}$ is the rate of spread of variance which is the relevant component of the turbulent velocity. The Weather Research and Forecasting (WRF) (Skamarock et al., 2005) 
model we use to drive SatPlume explicitly calculates turbulent kinetic energy (TKE) as

$\mathrm{TKE}=\frac{1}{2} \boldsymbol{u}_{\mathrm{T}} \cdot \boldsymbol{u}_{\mathrm{T}}$,

where $\boldsymbol{u}_{\mathrm{T}}$ is the turbulent velocity vector. Assuming isotropic turbulence all components of $\boldsymbol{u}_{\mathrm{T}}$ are thus equal:

$\boldsymbol{\phi}_{\mathrm{T}}=\sqrt{\frac{2 \mathrm{TKE}}{3}}$.

One complication we do not address here is the finite size of most sources. Equation (4) applies to point sources. Strictly speaking it must be integrated over all points in a finite source region. For large source regions this will yield a plume which, close to the source, has more sharply cut-off edges than a Gaussian from a point source. For the source resolutions we consider here this is not a major problem.

\subsection{Satellite observation operator}

The observation operator is the mathematical function (or computer code) which maps simulated concentrations in the model to a simulated satellite observation. Two properties of this operator are important in a theoretical study like this: how many samples will be obtained and how much smoothing of the concentration field is performed by the measurement process.

\subsubsection{Sampling density}

The viewing geometry of a geostationary measurement coupled with the albedo of water in the near-infrared precludes any useful measurements over water. We also assume no measurements are possible at solar zenith angles $>70^{\circ}$. Beyond this we need to estimate the number of scenes with low enough cloud and aerosol optical depth to allow a good retrieval. Following experience from GOSAT (O'Dell et al., 2012), we set an optical depth threshold of 0.3. To eliminate cloud shadowing effects, we also require clear sky (with the same threshold) between the entry and exit points of the sun-scene-satellite ray. We use an effective scale height of the atmosphere at $10 \mathrm{~km}$. We must calculate the distance between the entry and exit points of the sun-earth-satellite path at this scale height. This will change greatly with time of day depending on whether the bearing of the satellite and sun are opposed or similar.

We need the sampling statistics relevant to our study period rather than any particular realization. To calculate these statistics we use backscatter measurements from the CALIPSO lidar. The high resolution of the CALIPSO data allows us to calculate the probability that all scenes within a given distance will meet the threshold. Note that under this criterion, the cloud shadowing constraint is stronger than that of the actual instrument footprint. One limitation of the
CALIPSO data is its limitation to one time of day. The different solar zenith angles at different times will still impose a diurnal cycle of sampling density.

\subsubsection{Smoothing}

The satellite measurement is of absorption along the sunscene-satellite light path, and so we must integrate along this path in the model. For traditional global inversion studies (e.g., Rayner and O'Brien, 2001) where the model layers are very thin compared to their horizontal extent, this is equivalent to a vertical integral since few paths will cross into neighboring columns. We cannot make this assumption.

One aspect which unambiguously degrades the ability to localize sources is the point spread function (PSF) of the instrument. This function accounts for the fact that the instrument does not measure at a point or even in a model grid cell (for the scales considered here), but the measurement integrates spatially with a defined weighting. We represent this with a two-dimensional double exponential function with length scales represented by the full width at half maximum as defined in Sect. 2.1.

In concrete terms, the viewing geometry is invariant for a given time of day and a sufficiently small domain since the elevation and bearing of the sun and satellite do not vary with position. Thus we calculate a three-dimensional weighting function representing the PSF (assumed constant with height) and the light path. We assume an invariant weighting function with pressure. To apply the observation operator we convolve this weighting function with the concentration distribution defined by a plume's position and extent.

\section{Behavior of plume model}

Figure 1 shows a snapshot after $6 \mathrm{~h}$ of emitting a tracer at $1 \mathrm{kgC} \mathrm{m}^{-2}$ year $^{-1}$ from a $3 \times 3 \mathrm{~km}$ grid cell near the center of the domain. This plume has been sampled with a simple column-integrated weighting function (left) and the GEOCARB observation operator (right). We can understand the peak value of the plume by calculating the steady-state response to such a source in the presence of a $3 \mathrm{~m} \mathrm{~s}^{-1}$ columnaveraged wind (close to the low-level wind speed for this period). For this calculation we convert the source into a mixing ratio tendency (effectively dividing by atmospheric mass) and multiply it by the residence time of an air parcel over our $3 \times 3 \mathrm{~km}$ source grid. This yields a value of $7.6 \times 10^{-3} \mathrm{ppm}$, rather similar to the values for both observation operators.

We see that the simple column-integral produces stronger and more focused responses than the GEOCARB observations. Discontinuities in the plot of this plume arise when it is advected more than one footprint in a single model time step. Differences are particularly clear near the source where the plume is narrow. The slantwise viewing geometry is a greater 

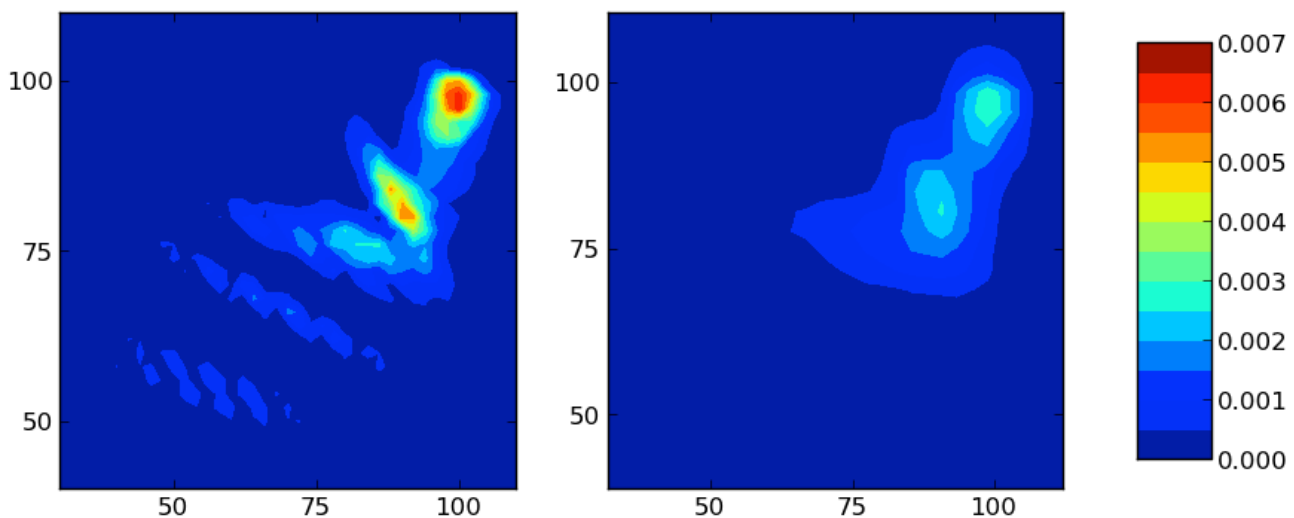

Figure 1. Concentration $(\mathrm{ppm})$ arising from source in a single $3 \times 3 \mathrm{~km}$ grid cell sampled according to the simple column-integrated (left) or instrumental (right) observation operator. The source has an emission rate of $1 \mathrm{kgC} \mathrm{m}^{2}$ year ${ }^{-1}$. Concentration is sampled after continuous emissions for $6 \mathrm{~h}$. The source has dimension $3 \mathrm{~km} \times 3 \mathrm{~km}$ and is centered at $x=y=101.5 \mathrm{~km}$. The $200 \mathrm{~km} \times 200 \mathrm{~km}$ domain is centered at the location of Shanghai $\left(31.2^{\circ} \mathrm{N}, 131.5^{\circ} \mathrm{E}\right)$. We plot only the southwest part of the domain.

cause of spreading than the PSF. Once the plume becomes sufficiently broad, the two observation operators are similar.

The plume broadening for this case is somewhat slower than the model used by Bovensmann et al. (2010). The main cause of the broadening is the impact of horizontal wind shear which tilts the plume with height and thus increases its projection on the ground. We have already noted there are few measurements of the rate of spread of column-integrated plumes. Testing our simple model at least against complete transport models such as WRF-Chem is an important topic for future work.

\section{Urban case}

\subsection{Experimental setup}

Our chosen domain is a $200 \times 200 \mathrm{~km}$ grid occupying the latitude and longitude of Shanghai. We make no attempt to mimic the structure of Shanghai, only the sampling conditions that would prevail there. Our test source uncertainty field is shown in Fig. 2. We stress again that only the prior uncertainties are shown. The domain consists of a nonurban region with low uncertainty $\left(1 \mathrm{kgC} \mathrm{m}^{-2}\right.$ year $\left.{ }^{-1}\right)$ surrounding an urban region of $100 \times 100 \mathrm{~km}$ with uncertainty of $10 \mathrm{kgC} \mathrm{m}^{-2}$ year $^{-1}$. Within this city is one power plant which is a point source with an uncertainty of $0.9 \mathrm{MtC}$ year $^{-1}$. Both the power plant and the nonurban hinterland have no CO source (we assume the power plant is combusting its fuel efficiently). The $\mathrm{CO}$ emission factor for the urban region is one of the variables we solve for in the inversion (see Sect. 2).

We observe this domain from a satellite in geostationary orbit at $110^{\circ} \mathrm{E}$. This generates a satellite zenith angle of $37^{\circ}$ and increases the footprint of satellite measurements to $6.3 \mathrm{~km}$ in the east-west and $5.1 \mathrm{~km}$ in the north-south. Use of

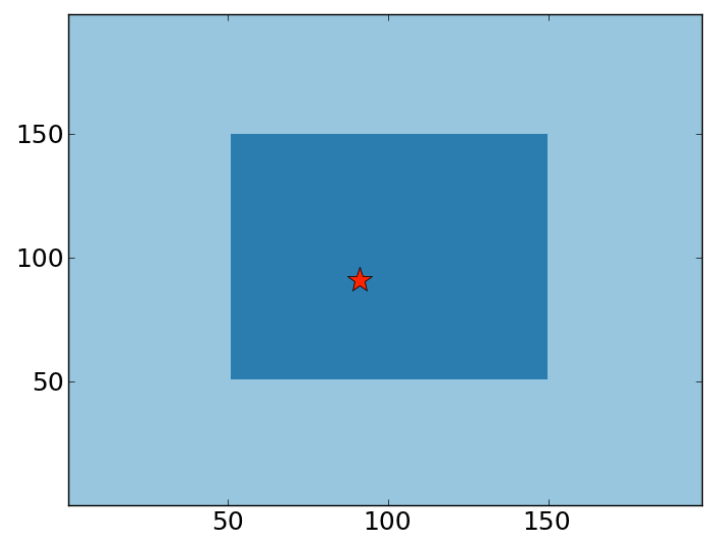

Figure 2. Prior flux uncertainty $\left(\mathrm{kgC} \mathrm{m}^{-2} \mathrm{year}^{-1}\right)$. The uncertainty values are $1 \mathrm{kgC} \mathrm{m}^{-2}$ year $^{-1}$ for the hinterland,

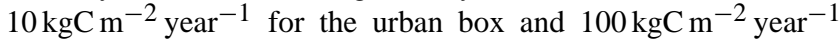
for the idealized power plant. The $200 \mathrm{~km} \times 200 \mathrm{~km}$ domain is centered at the location of Shanghai $\left(31.2^{\circ} \mathrm{N}, 131.5^{\circ} \mathrm{E}\right)$.

the zenith angle and CALIPSO backscatter filters generates 13056 measurements during the 6-day study period.

We solve for sources on a $3 \times 3 \mathrm{~km}$ grid. For $\mathrm{CO}_{2}$ sources we divide the day into four $6 \mathrm{~h}$ blocks (starting at 00:00, 06:00, 12:00 and 18:00 UTC) while we assume the CO emission factor is constant for each location. Our study period is 6 days, and we solve for average sources and emission factors over the 6 days. We assume we only make measurements over the urban zone in the center of the domain. This is not realistic since the instrument scan covers a large domain, but we wish to investigate the impact of running inversions regionally for which there are always unknown fluxes outside the domain which may impact measurements we are using. We can always improve our knowledge of these following either Lauvaux et al. (2009a) or Rödenbeck et al. (2009). 


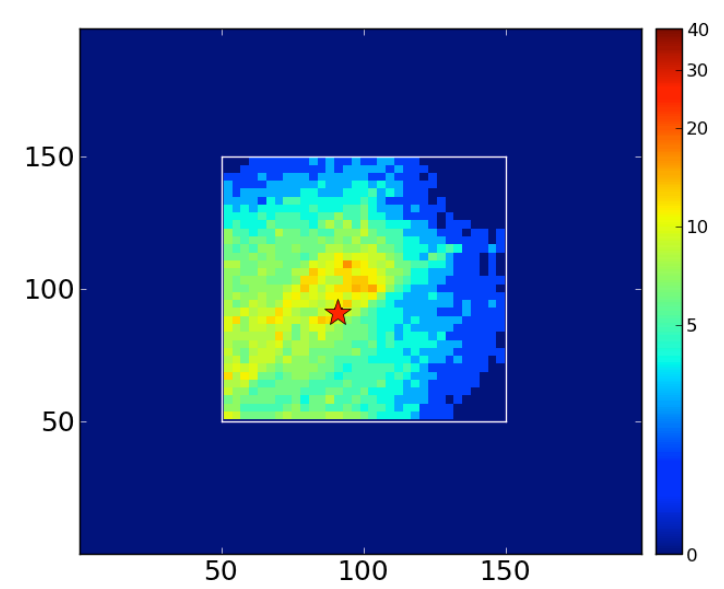

Figure 3. Reduction in uncertainty of 6-day averaged fluxes for the time 00:00-06:00 UTC $\left(100 \times\left(1-\frac{\sigma_{\text {POST }}}{\sigma_{\text {PRIOR }}}\right)\right)$ for $\mathrm{CO}_{2}$ fluxes in the case with both $\mathrm{CO}$ and $\mathrm{CO}_{2}$ measurements. The red star shows the location of the power plant. The $200 \mathrm{~km} \times 200 \mathrm{~km}$ domain is centered at the location of Shanghai $\left(31.2^{\circ} \mathrm{N}, 131.5^{\circ} \mathrm{E}\right)$.

For $\mathrm{CO}$ we assume a $\mathrm{CO}_{2}$ emission factor of $50 \mathrm{ppbpm}^{-1}$ with an uncertainty of $10 \%$. As noted in Sect. 2.2 the impact of the uncertainty in the emission factor depends on the value of the $\mathrm{CO}_{2}$ emissions themselves. We set these at 10 times the uncertainty for the urban box; both the power plant and the biospheric hinterland have no $\mathrm{CO}$ emissions.

Driving meteorology is taken from a 6-day run of WRF. This model was run for the period 6-12 June 2012 for a domain which includes the latitude and longitude of Shanghai. We are not attempting to replicate conditions at Shanghai itself, so we have not excluded any measurements over water. WRF was run in a three-level nested configuration at resolutions $18 \mathrm{~km}, 6 \mathrm{~km}$ and $2 \mathrm{~km}$. The meteorological variables at the outer boundaries were nudged towards analyses from the European Centre for Medium Range Weather Forecasting Interim Reanalysis (ERA-Interim) (Dee et al., 2011). Our simple plume model requires the three velocity components and turbulent kinetic energy from WRF. These are output every $30 \mathrm{~min}$ on the inner $200 \times 200 \mathrm{~km}$ domain.

\subsection{Results}

Figure 3 shows the reduction of uncertainty afforded by combined measurements of $\mathrm{CO}_{2}$ and $\mathrm{CO}$. The targeted emission is from 00:00 to 06:00 UTC and averaged over 6 days. The structure is similar to that of the prior uncertainty in Fig. 2. This reflects the general result that reduction of uncertainty favors higher uncertainties. If we calculated absolute uncertainty instead, the biospheric hinterland would still have the lowest uncertainty even after the inversion. Within the urban box there is a gradual weakening of uncertainty reduction as we move from northeast to southwest. This follows from the prevailing wind direction already noted in Fig. 1; tracers from sources in the northeast quadrant have a longer trajectory over the observed region than those from the southwest. As might be expected the strongest reduction occurs for the strong point source mimicking a power plant.

To interpret the magnitude of these reductions, we can compare them with the uncertainties produced by Polonsky et al. (2013). They estimated the source strength of an isolated power plant with a set of measurements representing several snapshots of its plume. They achieved an uncertainty of about $10 \%$ of their $3.5 \mathrm{MtC}_{\text {year }}{ }^{-1}$ source. Our initial uncertainty of $0.9 \mathrm{MtC}^{-1} \mathrm{yr}^{-1}$ is reduced by about $35 \%$ to about $0.6 \mathrm{MtC}_{\mathrm{C}} \mathrm{ear}^{-1}$. This is nearly twice that of Polonsky et al. (2013), a difference almost entirely due to the confounding impact of the thousands of other source components in our case. These add noise to any attempt to retrieve the power-plant emission alone.

\subsection{Tests of observability}

We can get some sense of the constraint of individual measurements by propagating the uncertainty in a prior source into the space of observations and comparing its magnitude with the observational uncertainty. For example, with the steady-state response calculated earlier, an uncertainty of $1 \mathrm{kgC} \mathrm{m}^{-2}$ year $^{-1}$ translates into an uncertainty of $\approx 0.007 \mathrm{ppm}$. The observational error on $\mathrm{CO}_{2}$ is set to $3 \mathrm{ppm}$, so it is clear that it will be hard to constrain uncertainties beyond this value. For a prior uncertainty of $10 \mathrm{kgC} \mathrm{m}^{-2}$ year $^{-1}$, the projected signal is $0.07 \mathrm{ppm}$. It will take approximately 1600 measurements to reduce the observational uncertainty to the same magnitude. For $\mathrm{CO}$ the case is quite different. For the $10 \mathrm{kgC} \mathrm{m}^{-2}$ year ${ }^{-1} \mathrm{CO}_{2}$ source and the emission factor of $50 \mathrm{ppb} \mathrm{ppm}^{-1}$, the projected signal is $3.5 \mathrm{ppb}$. With an observational uncertainty of $10 \mathrm{ppb}$, this only requires about 10 measurements to produce an observable signal. Thus it is clear that the CO measurements play a vital role in constraining combustion sources. The uncertainty in the emission factor, coupled with a reasonable prior value for the source, produces another uncertainty which must be added quadratically to the observational uncertainty. With a source of $100 \mathrm{kgC} \mathrm{m}^{-2} \mathrm{year}^{-1}$ and an emission factor uncertainty of $5 \mathrm{ppb} \mathrm{ppm}^{-1}$, this contributes $3.5 \mathrm{ppb}$ extra uncertainty, only making a small additional contribution.

The above calculations give guidance to what we can expect from an inversion, but they are a pessimistic analysis of the problem. That is because the inversion does not depend on individual measurements but rather the detection of structures in the concentration which are signatures of particular source components. Here, as in many inverse calculations, the system can make reliable inferences about an unknown when its imprint on any single observation is smaller than the observational noise. 


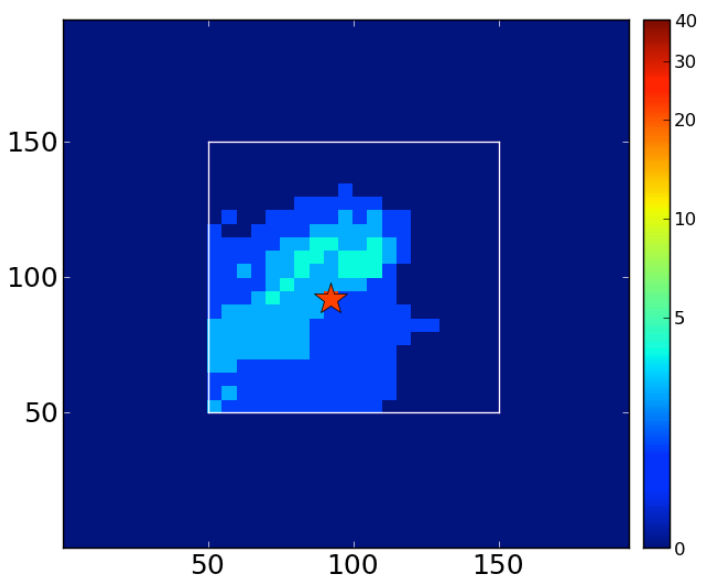

Figure 4. Reduction in uncertainty of 6-day averaged fluxes for the time 00:00-06:00 UTC $\left(100 \times\left(1-\frac{\sigma_{\text {POST }}}{\sigma_{\text {PRIOR }}}\right)\right)$ for $\mathrm{CO}_{2}$ fluxes in the case with only $\mathrm{CO}_{2}$ measurements. The red star shows the location of the power plant. The $200 \mathrm{~km} \times 200 \mathrm{~km}$ domain is centered at the location of Shanghai $\left(31.2^{\circ} \mathrm{N}, 131.5^{\circ} \mathrm{E}\right)$.

\subsection{Using $\mathrm{CO}_{2}$ only}

The preceding analysis highlights the importance of the $\mathrm{CO}$ measurements to the uncertainty reduction and suggests the problem will be difficult with only $\mathrm{CO}_{2}$ measurements. This indeed turns out to be the case. Figure 4 shows the same error reduction calculation using only $\mathrm{CO}_{2}$ measurements and for the same period but at a source resolution of $5 \times 5 \mathrm{~km}$. This raises the residence time and hence the steady-state response and similarly produces stronger Jacobians from the plume model. We reduce the intensity of the power plant so that its integrated uncertainty remains at $0.9 \mathrm{MtC}_{\text {year }}{ }^{-1}$. The uncertainty reduction on the power plant is about two-thirds as strong as for the combined measurement case, but the constraint on the weaker urban sources is much poorer. The difference in the power-plant constraint occurs because the combined case can constrain the other urban sources which confound the estimate of the power plant.

\section{Methane case}

For simplicity we use the same meteorological drivers for our methane case. Our test domain here is a compromise between constraining emissions from rice agriculture and industrial methane sources. The uncertainty in methane emissions for rice agriculture is listed by the UNFCCC guidelines as $12.9 \mathrm{~kg} \mathrm{CH}_{4} \mathrm{~km}^{-2} \mathrm{~h}^{-1}$. Work of Karion et al. (2013) suggested much larger emissions (and consequently uncertainties) for a natural gas field. We thus chose a prior uncertainty 3 times the UNFCCC value. Following the $\mathrm{CO}_{2}$-only example we solve for a source resolution of $5 \times 5 \mathrm{~km}$. We retain most other aspects of the measurement system, particularly the unmeasured zone at the edge of the domain.

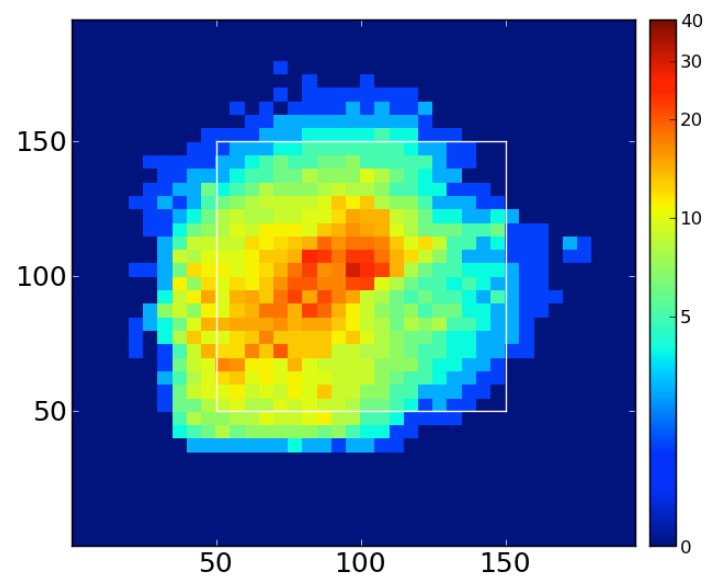

Figure 5. Reduction in uncertainty of 6-day averaged fluxes for the time 00:00-06:00 UTC $\left(100 \times\left(1-\frac{\sigma_{\text {POST }}}{\sigma_{\text {PRIOR }}}\right)\right)$ for $\mathrm{CH}_{4}$ fluxes. The $200 \mathrm{~km} \times 200 \mathrm{~km}$ domain is centered at the location of Shanghai $\left(31.2^{\circ} \mathrm{N}, 131.5^{\circ} \mathrm{E}\right)$.

\subsection{Results}

Using the same calculation for the steady-state response as for $\mathrm{CO}_{2}$ sources, we expect a signal of $\approx 4 \mathrm{ppb}$. Comparing this to the $18 \mathrm{ppb}$ observational error, we see an observability close to the $\mathrm{CO}$ measurement. The actual error reductions are shown in Fig. 5 (again for the 6-day average from 00:00 to 06:00 UTC) with values, indeed, close to those for the combined measurement case.

\section{Discussion}

The foregoing results seem to offer some promise for the detection of regional emissions from a feasible satellite instrument. As usual, there are many questions that need to be answered if we move towards implementing such an instrument. The first of these, already noted in the exploratory paper of Rayner and O'Brien (2001), concerns the information content of suites of GEOCARB measurements. This is particularly critical here where we have noted the large disparity between the observational error and the propagation of source uncertainties into concentration space (Sect. 4.3). At large scale the impact of observational biases (e.g., Crisp et al., 2012) seems rather serious (e.g., Chevallier et al., 2007). There are two reasons for optimism in the GEOCARB case. Firstly, although we have used $3 \mathrm{ppm}$ as our observational error, the study of Polonsky et al. (2013) produced much smaller scatter in their retrievals. Secondly the retrieval bias is largely driven by aerosol. If the aerosol is homogeneous over the domain of our inversion, this will be manifested in a global offset which we can include in the inversion. Using this assumption would require rigorous analysis of residuals to detect when it was breaking down. How 
aerosol contamination will affect retrievals at different scales is an important topic for future work.

The next question concerns the modeling. We cannot assess this properly with SatPlume which only tries to capture the statistics of plumes. We need to ensure that we can backtrack the column-integrated observation of a plume to its source. One way to test this is in forward experiments where we compare measurements and models of concentration near an isolated power plant. An example was presented by Utembe et al. (2013). They found that in situ measurements showed strong signatures of the power-station plume but were hard to model with several current generation transport and plume dispersion models. This was mainly due to the difficulty of simulating plume touchdown, an example of the difficulties of modeling vertical transport. Ground-based column-integrated measurements produced higher signal-tonoise ratio once these model errors were accounted for and consequently produced more accurate inverse estimates of the power-plant emission.

Another modeling problem is the use of $\mathrm{CO}$ as a combustion tracer. Although we made only weak assumptions about the spatial structure of $\boldsymbol{E}$ in Eq. (2), we did assume a $10 \%$ uncertainty on this value and no temporal variability. To test the importance of this assumption, we repeated the baseline case with a $100 \%$ uncertainty on $\boldsymbol{E}$. Uncertainty reduction was weakened by about $2 \%$ for the power plant and about $20 \%$ for the urban grid points. Uncertainty on $\boldsymbol{E}$ itself was reduced from the $100 \%$ prior value. In an operating inversion system, improved information on $\boldsymbol{E}$ would be used in subsequent inversions. Improved knowledge of variations in $\boldsymbol{E}$ is a matter for future research.

The limitation of the measurements to daytime poses a problem for their use in any regulatory framework. There is an obvious possibility of "hiding" emissions at night. One ameliorating factor is the ability to constrain area-integrated emissions even at night. This occurs because the concentration arising from an area-integrated source (such as a city) is still visible the next morning, even if the rate of plume spread means individual sources within the city can no longer be determined. This will depend on whether the city is sufficiently isolated to separate its area-integrated plume from neighboring sources.

The same problem occurs seasonally. The limit of $70^{\circ}$ on the solar zenith angle means that no observations will be made beyond $50^{\circ}$ in the winter hemisphere. This problem is common to all passive instruments and highlights the need for multiple complementary measurement approaches.

\section{Conclusions}

We have investigated the capacity of trace gas measurements from a geostationary satellite to constrain regional sources and sinks. Specifically, measurements of $\mathrm{CO}_{2}, \mathrm{CO}$ and $\mathrm{CH}_{4}$ taken with feasible precision and sampling density can significantly improve knowledge of fluxes at scales from 10 to $30 \mathrm{~km}^{2}$. The improvement comes despite the fact that individual measurements have a poor signal-to-noise ratio when compared to the signal projected from most sources. The reason is the imaging capability of the system which is capable of discerning the structure of plumes in apparently noisy observations.

The most powerful measurement is the $\mathrm{CO}$ which, despite weak assumptions about the emission factor, provides a better signal-to-noise ratio on combustion sources than the $\mathrm{CO}_{2}$ measurement. The $\mathrm{CO}$ measurement also allows clearer identification of the power-plant emissions despite the fact that we assume the plant does not emit CO. Overall, the strength of the regional constraint suggests such measurements could play an important role in both carbon cycle science and policy in future.

Acknowledgements. Rayner is in receipt of an Australian Professorial Fellowship (DP1096309).

Edited by: H. Worden

\section{References}

Bovensmann, H., Buchwitz, M., Burrows, J. P., Reuter, M., Krings, T., Gerilowski, K., Schneising, O., Heymann, J., Tretner, A., and Erzinger, J.: A remote sensing technique for global monitoring of power plant $\mathrm{CO}_{2}$ emissions from space and related applications, Atmos. Meas. Tech., 3, 781-811, doi:10.5194/amt-3-781-2010, 2010.

Chevallier, F., Bréon, F.-M., and Rayner, P. J.: The Contribution of the Orbiting Carbon Observatory to the Estimation of $\mathrm{CO}_{2}$ Sources and Sinks: Theoretical Study in a Variational Data Assimilation Framework, J. Geophys. Res., 112, D09307, doi:10.1029/2006JD007375, 2007.

Chevallier, F., Engelen, R. J., Carouge, C., Conway, T. J., Peylin, P., Pickett-Heaps, C., Ramonet, M., Rayner, P. J., and Xueref-Remy, I.: AIRS-based vs. flask-based estimation of carbon surface fluxes, J. Geophys. Res., 114, D20303, doi:10.1029/2009JD012311, 2009.

Crisp, D., Fisher, B. M., O’Dell, C., Frankenberg, C., Basilio, R., Bösch, H., Brown, L. R., Castano, R., Connor, B., Deutscher, N. M., Eldering, A., Griffith, D., Gunson, M., Kuze, A., Mandrake, L., McDuffie, J., Messerschmidt, J., Miller, C. E., Morino, I., Natraj, V., Notholt, J., O’Brien, D. M., Oyafuso, F., Polonsky, I., Robinson, J., Salawitch, R., Sherlock, V., Smyth, M., Suto, H., Taylor, T. E., Thompson, D. R., Wennberg, P. O., Wunch, D., and Yung, Y. L.: The ACOS $\mathrm{CO}_{2}$ retrieval algorithm - Part II: Global XCO2 data characterization, Atmos. Meas. Tech., 5, 687-707, doi:10.5194/amt-5-687-2012, 2012.

Dee, D. P., Uppala, S. M., Simmons, A. J., Berrisford, P., Poli, P., Kobayashi, S., Andrae, U., Balmaseda, M. A., Balsamo, G., Bauer, P., Bechtold, P., Beljaars, A. C. M., van de Berg, L., Bidlot, J., Bormann, N., Delsol, C., Dragani, R., Fuentes, M., Geer, A. J., Haimberger, L., Healy, S. B., Hersbach, H., Hólm, E. V., Isaksen, L., Kallberg, P., Köhler, M., Matricardi, M., McNally, A. P., Monge-Sanz, B. M., Morcrette, J.-J., Park, B.-K., Peubey, 
C., de Rosnay, P., Tavolato, C., Thépaut, J.-N., and Vitart, F.: The ERA-Interim reanalysis: configuration and performance of the data assimilation system, Q. J. Roy. Meteorol. Soc., 137, 553597, doi:10.1002/qj.828, 2011.

Engelen, R. J., Serrar, S., and Chevallier, F.: Four-dimensional data assimilation of atmospheric $\mathrm{CO}_{2}$ using AIRS observations, J. Geophys. Res., 114, D03303, doi:10.1029/2008JD010739, 2009.

Enting, I. G., Trudinger, C. M., and Francey, R. J.: A synthesis inversion of the concentration and $\delta^{13} \mathrm{C}$ of atmospheric $\mathrm{CO}_{2}$, Tellus, 47B, 35-52, 1995.

Houweling, S., Breon, F.-M., Aben, I., Rödenbeck, C., Gloor, M., Heimann, M., and Ciais, P.: Inverse modeling of $\mathrm{CO}_{2}$ sources and sinks using satellite data: a synthetic inter-comparison of measurement techniques and their performance as a function of space and time, Atmos. Chem. Phys., 4, 523-538, doi:10.5194/acp-4523-2004, 2004.

Hungershoefer, K., Breon, F.-M., Peylin, P., Chevallier, F., Rayner, P., Klonecki, A., Houweling, S., and Marshall, J.: Evaluation of various observing systems for the global monitoring of $\mathrm{CO}_{2}$ surface fluxes, Atmos. Chem. Phys., 10, 10503-10520, doi:10.5194/acp-10-10503-2010, 2010.

Karion, A., Sweeney, C., Pétron, G., Frost, G., Michael Hardesty, R., Kofler, J., Miller, B. R., Newberger, T., Wolter, S., Banta, R., Brewer, A., Dlugokencky, E., Lang, P., Montzka, S. A., Schnell, R., Tans, P., Trainer, M., Zamora, R., and Conley, S.: Methane emissions estimate from airborne measurements over a western United States natural gas field, Geophys. Res. Lett., 48, 67166733, doi:10.1002/grl.50811, 2013.

Krings, T., Gerilowski, K., Buchwitz, M., Reuter, M., Tretner, A., Erzinger, J., Heinze, D., Pflüger, U., Burrows, J. P., and Bovensmann, H.: MAMAP - a new spectrometer system for columnaveraged methane and carbon dioxide observations from aircraft: retrieval algorithm and first inversions for point source emission rates, Atmos. Meas. Tech., 4, 1735-1758, doi:10.5194/amt-41735-2011, 2011.

Kumer, J. B., Rairden, R. L., Roche, A. E., Chevallier, F., Rayner, P. J., and B. Moore III.: Progress in development of Tropospheric Infrared Mapping Spectrometers (TIMS): geoCARB greenhouse gas (GHG) application, in: Proceedings of the SPIE, 8867 pp., doi:10.1117/12.2022668, 2013.

Kuze, A., Suto, H., Nakajima, M., and Hamazaki, T.: Thermal and near infrared sensor for carbon observation Fouriertransform spectrometer on the Greenhouse Gases Observing Satellite for greenhouse gases monitoring, Appl. Opt., 48, 67166733, doi:10.1364/AO.48.006716, 2009.

Lauvaux, T., Gioli, B., Rayner, P. J., Chevallier, F., Miglietta, F., Ceschia, E., Elbers, J. A., Hutjes, R., Legain, D., and Uliasz, M.: Bridging the gap between atmospheric concentrations and local ecosystem measurements, Geophys. Res. Lett., 36, L19809, doi:10.1029/2009GL039574, 2009a.

Lauvaux, T., Pannekoucke, O., Sarrat, C., Chevallier, F., Ciais, P., Noilhan, J., and Rayner, P. J.: Structure of the transport uncertainty in mesoscale inversions of $\mathrm{CO} 2$ sources and sinks using ensemble model simulations, Biogeosciences, 6, 1089-1102, doi:10.5194/bg-6-1089-2009, 2009b.

Law, R. M., Rayner, P. J., Steele, L. P., and Enting, I. G.: Data and modelling requirements for $\mathrm{CO}_{2}$ inversions using high frequency data, Tellus, 55B, 512-521, doi:10.1034/j.16000889.2003.00029.x, 2003.
Miller, C. E., Crisp, D., DeCola, P. L., Olsen, S. C., Randerson, J. T., Michalak, A. M., Alkhaled, A., Rayner, P., Jacob, D. J., Suntharalingam, P., Jones, D., Denning, A. S., Nicholls, M. E., Doney, S. C., Pawson, S., Boesch, H., Connor, B. J., Fung, I. Y., O’Brien, D., Salawitch, R. J., Sander, S. P., Sen, B., Tans, P., Toon, G. C., Wennberg, P. O., Wofsy, S. C., Yung, Y. L., and Law, R. M.: Precision requirements for space-based $\mathrm{XCO}_{2}$ data, J. Geophys. Res., 112, 10314, doi:10.1029/2006JD007659, 2007.

O’Dell, C. W., Connor, B., Bösch, H., O’Brien, D., Frankenberg, C., Castano, R., Christi, M., Eldering, D., Fisher, B., Gunson, M., McDuffie, J., Miller, C. E., Natraj, V., Oyafuso, F., Polonsky, I., Smyth, M., Taylor, T., Toon, G. C., Wennberg, P. O., and Wunch, D.: The ACOS $\mathrm{CO}_{2}$ retrieval algorithm - Part 1: Description and validation against synthetic observations, Atmos. Meas. Tech., 5, 99-121, doi:10.5194/amt-5-99-2012, 2012.

Parazoo, N. C., Bowman, K., Frankenberg, C., Lee, J.-E., Fisher, J. B., Worden, J., Jones, D. B. A., , Berry, J., Collatz, G. J., Baker, I. T., Jung, M., Liu, J., Osterman, G., O’Dell, C., Sparks, A., Butz, A., Guerlet, S., Yoshida, Y., Chen, H., and Gerbig, C.: Interpreting seasonal changes in the carbon balance of southern Amazonia using measurements of $\mathrm{XCO}_{2}$ and chlorophyll fluorescence from GOSAT, Geophys. Res. Lett., 40, 2829-2833, doi:10.1002/grl.50452, 2013.

Polonsky, I. N., O’Brien, D. M., Kumer, J. B., O’Dell, C. W., and the geoCARB Team: Performance of a geostationary mission, geoCARB, to measure $\mathrm{CO}_{2}, \mathrm{CH} 4$ and $\mathrm{CO}$ column-averaged concentrations, Atmos. Meas. Tech., 7, 959-981, doi:10.5194/amt7-959-2014, 2014.

Rayner, P. J. and O'Brien, D. M.: The utility of remotely sensed $\mathrm{CO}_{2}$ concentration data in surface source inversions, Geophys. Res. Lett., 28, 175-178, 2001.

Rayner, P. J., Enting, I. G., and Trudinger, C. M.: Optimizing the $\mathrm{CO}_{2}$ Observing Network for Constraining Sources and Sinks, Tellus, 48B, 433-444, 1996.

Rödenbeck, C., Gerbig, C., Trusilova, K., and Heimann, M.: A twostep scheme for high-resolution regional atmospheric trace gas inversions based on independent models, Atmos. Chem. Phys., 9, 5331-5342, doi:10.5194/acp-9-5331-2009, 2009.

Schuh, A. E., Lauvaux, T., West, T. O., Denning, A. S., Davis, K. J., Miles, N., Richardson, S., Uliasz, M., Lokupitiya, E., Cooley, D., Andrews, A., and Ogle, S.: Evaluating atmospheric $\mathrm{CO}_{2}$ inversions at multiple scales over a highly-inventoried agricultural landscape, Glob. Change Biol., 19, doi:10.1111/gcb.12141, in press, 2013.

Skamarock, W. C., Klemp, J. B., Dudhia, J., Gill, D. O., Barker, D. M., Wang, W., and Powers, J. G.: A Description of the Advanced Research WRF Version 2, Tech. rep., National center for Atmospheric Research, 2005.

Tarantola, A.: Inverse Problem Theory and Methods for Model Parameter Estimation, SIAM (ISBN 0-89871-572-5), 2004.

Utembe, S., Lunney, C., Jones, N., Rayner, P., Genkova, I., Griffith, D., O'Brien, D., and Clark, A.: Modelling the column-integrated signal from a point-source: Progress and Problems, in: Proceedings of the 9th International Workshop on Greenhouse Gas Measurements from Space, 27 pp., Japan Aerospace Exploration Agency (JAXA), Yokohama, Japan, available at: http://iwggms.azurewebsites.net/ IWGGMS-9_Abstract_Collection.pdf (last access: 1 October 2014), 2013. 